\title{
Cytological analysis of ginseng carpel development
}

Article in Protoplasma · February 2017

DOI: $10.1007 /$ s00709-017-1081-4

CITATIONS

0

9 authors, including:

Yu-Jin Kim

Kyung Hee University

106 PUBLICATIONS 943 CITATIONS

SEE PROFILE

\section{Deok-Chun Yang}

Kyung Hee University

579 PUBLICATIONS $\quad 4,432$ CITATIONS

SEE PROFILE

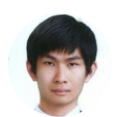

Johan Sukweenadhi

Universitas Surabaya

29 PUBLICATIONS 93 CITATIONS

SEE PROFILE

\section{Dabing Zhang}

Shanghai Jiao Tong University

187 PUBLICATIONS 5,257 CITATIONS

SEE PROFILE

Some of the authors of this publication are also working on these related projects:

Project Soil Microbial Community analysis View project

Project Functional characterization of pollen development genes in rice View project 


\section{Cytological analysis of ginseng carpel development}

\section{Jeniffer Silva, Yu-Jin Kim, Dexin Xiao,}

Johan Sukweenadhi, Tingting Hu, WooSaeng Kwon, Jianping Hu, Deok-Chun Yang \& Dabing Zhang

\section{Protoplasma}

An International Journal of Cell Biology

ISSN 0033-183X

Protoplasma

DOI 10.1007/s00709-017-1081-4

\section{Protoplasma}

An International Journal of Cell Biology
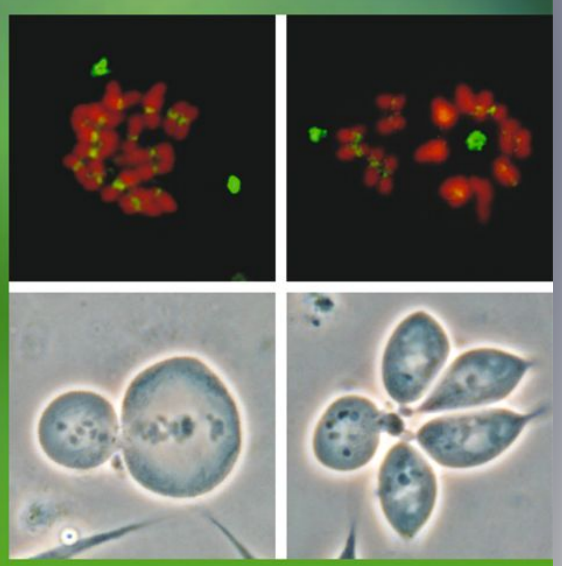

Springer 
Your article is protected by copyright and all rights are held exclusively by SpringerVerlag Wien. This e-offprint is for personal use only and shall not be self-archived in electronic repositories. If you wish to self-archive your article, please use the accepted manuscript version for posting on your own website. You may further deposit the accepted manuscript version in any repository, provided it is only made publicly available 12 months after official publication or later and provided acknowledgement is given to the original source of publication and a link is inserted to the published article on Springer's website. The link must be accompanied by the following text: "The final publication is available at link.springer.com". 


\title{
Cytological analysis of ginseng carpel development
}

\author{
Jeniffer Silva ${ }^{1}$ - Yu-Jin Kim ${ }^{1,2}$ (D) Dexin Xiao ${ }^{2}$ Johan Sukweenadhi ${ }^{1}$ Tingting $\mathrm{Hu}^{2}$ • \\ Woo-Saeng Kwon ${ }^{1} \cdot$ Jianping $\mathrm{Hu}^{2,3} \cdot$ Deok-Chun Yang ${ }^{1}$ - Dabing Zhang ${ }^{2}$
}

Received: 17 August 2016 / Accepted: 25 January 2017

(C) Springer-Verlag Wien 2017

\begin{abstract}
Panax ginseng Meyer, commonly known as ginseng, is considered one of the most important herbs with pharmaceutical values due to the presence of ginsenosides and is cultivated for its highly valued root for medicinal purposes. Recently, it has been recognized that ginseng fruit contains high contents of triterpene such as ginsenoside Re as pharmaceutical compounds. However, it is unclear how carpel, the female reproductive tissue of flowers, is formed during the three-year-old growth before fruit is formed in ginseng plants. Here, we report $P$. ginseng carpel development at the cytological level, starting from the initial stage of ovule development to seed development. The carpel of $P$. ginseng is composed of two free stigmas, two free styles, and one epigynous bilocular ovary containing one ovule in each locule. Based on our cytological study, we propose that the female reproductive development in $P$. ginseng can be
\end{abstract}

Handling Editor: Liwen Jiang

Yu-Jin Kim

yujinkim@khu.ac.kr

$\triangle$ Deok-Chun Yang

dcyang@khu.ac.kr

$\checkmark$ Dabing Zhang

zhangdb@sjtu.edu.cn

1 Department of Oriental Medicine Biotechnology and Graduate School of Biotechnology, College of Life Science, Kyung Hee University, Yongin 446-701, South Korea

2 Joint International Research Laboratory of Metabolic and Developmental Sciences, Shanghai Jiao Tong University-University of Adelaide Joint Centre for Agriculture and Health, School of Life Sciences and Biotechnology, Shanghai Jiao Tong University, Shanghai 20040, China

3 Department of Energy Plant Research Laboratory, Michigan State University, East Lansing, MI 48824, USA classified into seven stages: early phase of ovule development, megasporogenesis, megagametogenesis, pre-fertilization, fertilization, post-fertilization, and seed development. We also describe the correlation of the female and male gametophyte development and compare morphological differences in carpel development between ginseng and other higher plants. One unique feature for ginseng seed development is that it takes 40 days for the embryo to develop to the early torpedo stage and that the embryo is small relative to the seed size, which could be a feature of taxonomic importance. This study will provide an integral tool for the study of the reproductive development and breeding of $P$. ginseng.

Keywords Panax ginseng · Ontogeny · Ovule · Ultrastructure $\cdot$ Stages of carpel development

\section{Introduction}

Sexual reproduction is a major process in the life cycle of flowering plants, as it is essential for seed production to generate a new population of offspring (Robert et al. 2015; Zhang et al. 2015). This process depends on highly specialized reproductive organs, stamen (male) and carpel (female), which are protected by flower buds until anthesis. Both reproductive organs have tightly coordinated mechanisms that are indispensable for effective fertilization and production of viable seeds (Vivian-Smith et al. 2001; Robert et al. 2015). Through the fusion of haploid gametes, fertilization initiates the development of a new diploid organism (Dresselhaus et al. 2016). Following fertilization, the ovule develops into a seed while the surrounding carpel differentiates into a fruit to complete a successful reproduction (Coombe 1976; Vivian-Smith et al. 2001). The major seed components, embryo and endosperm, are formed after the fusion of two sperm cells with two dimorphic female gametes, the egg and the central cell, respectively (Dresselhaus et al. 2016). Successful 
female reproductive development has to undergo several critical events, starting with the specification of the megasporocyte, which subsequently produces a functional megaspore (megasporogenesis) that afterwards forms the embryo sac (megagametogenesis). Through embryogenesis, the embryo sac develops into an embryo (Reiser and Fischer 1993).

Angiosperm carpels normally display the polygonum type of embryo sac, ovule with the anatropous curvature, and the nuclear endosperm. Although carpel development in angiosperms share common characteristics, flower, carpel, and ovule in different species show a variety of developmental features, which have been investigated in a wide number of plant species such as Arabidopsis (Arabidopsis thaliana) (Schneitz et al. 1995), Iris tenax Douglas (Wilson 2001), Triteleia sp. (Berg 2003), Vochysiaceae (Litt and Stevenson 2003), Araliaceae (Costello and Motley 2004; Sokoloff et al. 2007; Oskolski et al. 2010), Panax sp. (Yu and Kim 1992; Venugopal et al. 2013; Qi et al. 2015), Cytisus striatus and C. multiflorus (Rodríguez-Riaño et al. 2006), Hydatellaceae (Rudall et al. 2008), Silene latifolia (Koizumi et al. 2009), Drosera x obovata (Rodondi et al. 2009), Psychotria carthagenensis and Rudgea macrophylla (Figueiredo et al. 2013), rice (Oryza sativa) (Kubo et al. 2013; Wu et al. 2016a, b), Taraxacum Wigg. (Musiał et al. 2013), Gaussia attenuata (Castaño et al. 2014), Coffea arabica (de Oliveira et al. 2014), and Encephalartos natalensis (Woodenberg et al. 2014). These studies clearly illustrate that as a vital sexual reproductive organ, the ovule is involved in many complex systematic interactions during flower development. As the ovule is contained in the carpel, it is needed to understand the structure and development of the carpel as a whole. Many significant events in the life cycle of a plant, such as the production of the female gametophyte with the egg cell via meiosis, guidance and attraction of the pollen tube (male gametes) at the micropyle - i.e., small opening formed from the integuments through which the pollen tube enters to fuse the with the egg cell, canalization of male gametes toward the egg cell via the nucellus and female gametophyte, protection of the female gametophyte-containing nucellus, double fertilization, and the development of the new sporocyte, are all completed within the carpel (Angenent and Colombo 1996; Wang and Ren 2008; Endress 2011). The anatomy and morphology of carpel in different plant species are divergent, showing specific characteristics in the number of stigmas, position of the ovary, number of locules and ovules per locule, ovule size, ovule curvature, number and thickness of integuments, nucellus thickness, type of embryo sac, placentation, endosperm, and embryogenesis.

The genus Panax L. belongs to the order Umbelliferales in the Araliaceae family and is commonly used for medicinal purpose. Among the 17 species in this genus, Panax ginseng Meyer is the most widely used because of its high pharmacological efficacy (Kim et al. 2015a). Propagation of ginseng plants is dependent on seeds produced via self-fertilization.
At the third growth year, they initiate flowering and generate seed and undergo active reproductive development by forming 30-50 flowers in an umbel inflorescence after the fourth year. Although studies on Panax L. about post-fertilization to seed development (Yu and Kim 1992; Venugopal et al. 2013; Qi et al. 2015) and anther development (Kim et al. 2015b) have conducted, it is still insufficient on understanding about carpel development. Elucidating and characterizing the carpel developmental events at a cytological level will be helpful to develop inter- and intra-specific hybrids, which displayed hybrid vigor on metabolite and plant yield (Kim et al. 2016), and identify genes at exact stages for hybridization barrier. In the present research, we studied carpel development in $P$. ginseng. First, we used light microscopic observations of transverse sections to analyze the complete ontogeny during carpel development and cellular changes during $P$. ginseng carpel development. We were able to divide the course of ginseng carpel developmental into seven stages, providing a comprehensive and detailed descriptive analysis at the ultrastructural level. In addition, we correlated female gametophyte development with anther development that was described in our previous report. Given the economic and medical importance of $P$. ginseng, in this study the timing of the occurrence of morphological events during reproductive development was investigated, aiming to improve the efficiency of ginseng production and breeding. We are providing a key asset in ginseng reproductive development that will allow interpreting defects and/or events derived from reproductive development, provide a basis knowledge for molecular analysis of genes involved in carpel and stamen, and it will represent an essential tool to select specific reproductive developmental stages for ginseng breeding.

\section{Materials and methods}

\section{Plant material}

To study carpel development, inflorescences of 5-year-old $P$. ginseng were collected from the ginseng field of Kyung Hee University (South Korea) from April to July (April 17, 23, May 1, 7, 12, 19, 25, June 1, 8, 15, 23, 29, and July 7) of 2015.

\section{Light microscopy of semi-thin sections}

Ginseng inflorescences at different stages were fixed using formalin-acetic acid alcohol (FAA, 50\% ethanol, 5\% glacial acetic acid, $3.7 \%$ formaldehyde). The fixed samples were dehydrated in a graded ethanol series $(70 \%, 80 \%, 90 \%$, and $100 \%)$ for $30 \mathrm{~min}$ per step and then embedded in Kulzer's Technovit 7100 cold polymerizing resin (Heraeus Kulzer GmbH Philipp-Reis-Straße 8/13, D-61273 Wehrheim/Ts) by preinfiltration, infiltration, and embedding at $45{ }^{\circ} \mathrm{C}$ (Igersheim and Cichocki 1996; Beeckman and Viane 2000; Zhang et al. 2013). Embedded samples were 
sectioned at 3-4 $\mu \mathrm{m}$ thickness using an Ultratome III ultramicrotome (LKB) and stained with $0.25 \%$ toluidine blue $\mathrm{O}$ (Chroma Gesellshaft Shaud) at $42{ }^{\circ} \mathrm{C}$. Bright-field photographs of the ovary sections were taken using a Nikon Eclipse 80i microscope and a Nikon DXM1200 digital camera.

\section{Scanning electron microscopy}

For scanning electron microscopy (SEM) examination, inflorescences were collected, fixed, and washed using the same procedure for semi-thin section except the dehydration procedure, which used 3 min treatment of 20, 30, 40, 50,60, 70, 80, 90, and $100 \%$ ethanol, respectively. After dehydration, samples were thoroughly dried at critical point (Leica EM CPD300). A Leica EM SCD050 ion sputter was used for aurum coating at 5-nm thickness. The aurum-coated samples were observed with a Hitachi S3400N scanning electron microscope.

\section{Image analysis}

Images were analyzed with the ImageJ version $1.49 \mathrm{~m}$ software (National Institutes of Health, USA) and the Fiji plugin. From ten samples at each developmental stage, more than five selected images of each stage samples were used for morphometric analysis on flower bud, stigma, ovules, and fruit.

\section{Results}

\section{Ginseng carpel development during plant morphogenesis}

$P$. ginseng is a slow-growing perennial herb that usually produces flowers in the third year of growth, when the stem develops three compound leaves, each with five leaflets, verticillate-i.e., having a circular arrangement, at the apex of the stem (Kim et al. 2015a, 2016). The inflorescence of $P$. ginseng consists of a single, terminal umbel-i.e., a rounded flower cluster in which the individual stalks arise from about the same point, with small flowers. Ginseng carpel is composed of three parts: two free stigmas, two free styles, and one ovary (monocarpus). The ovary is epigynous - i.e., located below the petals and sepals, receptacular-i.e., the ovary is embedded in the floral receptacle, and bicarpellar-i.e., the ovary has two locules and a single ovule in each locule (Fig. 1). These are consistent with general characteristics of the Araliaceae family and the closely related family, Umbelliferae (Costello and Motley 2004). The mature ovule is anatropous - i.e., the ovule is completely inverted so that the micropyle is situated next to the funicle, bitegmic-i.e., the ovule has two integuments and tenuinucellate - i.e., ovule with thin nucellus (Fig. 1). The single ovary develops into a simple flesh fruit (berry) and splits to release the seeds when ripe into two one-seeded mericarps (Sachs and Bennett 2011; Singh 2010).

We used light microscopy of semi-thin sections to reveal the cytological aspects of $P$. ginseng carpel development prior
Fig. 1 Structure of a $P$. ginseng flower. $P$. ginseng flower is monocarpus and has an epigynous and bilocular carpellate ovary with a single ovule in each locule, and anatropous, bitegmic, and tenuinucellate ovules. Cartoon is not drawn to scale

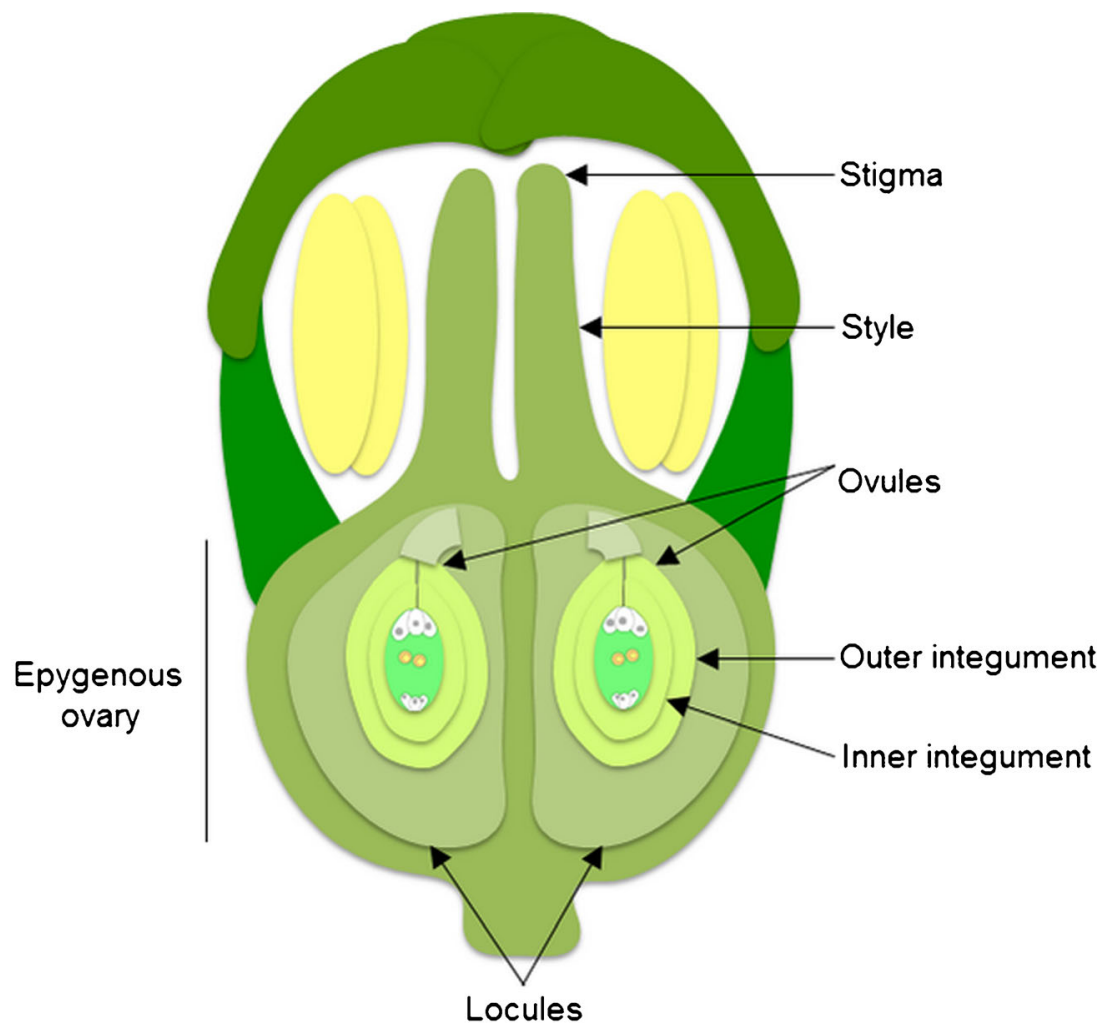


to seed formation. $P$. ginseng carpel exhibits distinctive features in different stages of plant morphology (Fig. 2). On the basis of visualized cellular events, we divided the carpel development of $P$. ginseng into seven stages (Fig. 3, Table 1).

\section{Stage 1-early phase of ovule development}

When ginseng plant exhibits a parasol kind of shape with unfolded leaves attached to the peduncle (Kim et al. 2015b; Fig. 2a), the inflorescence has $\sim 8-15$ flower buds (Kim et al. 2015b; Fig. 2h), each at $0.9686 \pm 0.04 \mathrm{~mm}$ in length (Fig. 4a), and stigmas that are each $0.3316 \pm 0.01 \mathrm{~mm}$ in length (Fig. 2o). Ovule primordium was initiated at the center of the ovary, from the placental tissues of carpel margins (Fig. 4b). Afterwards, each ovule primordium grows in opposite directions and finally settling at $90^{\circ}$ from the center (Fig. 4c). We denominated this stage as stage 1-I, at 1 to 5 days after sprouting (DAS). Later, at 5 to 10 DAS, the ovule primordium elongates, becoming finger-like (Fig. 4d), and then undergoes the first meiotic division (Fig. 4e), which we named stage 1-II. Within the anther, the megasporocyte undergoes the first meiotic division (Fig. 4f, g).

\section{Stage 2-megasporogenesis}

During stage 2-I, at 10 to 14 DAS, the unfolded leaves detach from the peduncle (Fig. 2b), the inflorescence holds more flower buds (Fig. 2i) that are $1.4220 \pm 0.02 \mathrm{~mm}$ in length (Fig. 5a) and the stigma $0.5000 \pm 0.01 \mathrm{~mm}$ in length. Within the ovary, a differentiated commissure and two locules are observed (Fig. 2p). The megaspore mother cell enlarges (Fig. 5b), while the integuments have initiated as small protuberances (Fig. 5c). The inner integument is composed of two cell layers while the outer integument is composed of one cell layer (Fig. 5d). Concurrently, the anther is undergoing the first meiotic division (Fig. 5(d1)). Afterwards, both integuments elongate and the megaspore mother cell undergoes the second meiotic division (Fig. 5e). During this stage, the anther is also under the formation of tetrads by meiotic division (Fig. 5(e1)). During stage 2-II, at 14-24 DAS, the outer integument surrounds both the inner integument and nucellus, and the nucellus is more prominent and becomes tenuinucellar (Fig. 5e).

\section{Stage 3-megagametogenesis}

At 24 to 31 DAS, when ginseng leaves are partially expanded and the inflorescence has $20-25$ flower buds (b; Fig. 2c, j), differentiated funicles have developed within the ovary, and the stigma length is $0.5598 \pm 0.01 \mathrm{~mm}$ (Fig. 2q). During this stage (stage 3), the four-nucleus embryo sac appears and the outer integument completely encloses both the inner integument and nucellus (Fig. 5f). Ultimately, these four nuclei divide and produce an eight-nucleus embryo sac, with four nuclei in the chalazal pole - i.e., the area below the antipodal cells, and four in the micropylar pole - i.e., the area at where the integuments form an opening for the pollen tube entry. Through this process, the embryo sac enlarges and the eight nuclei undergo reorganization and cellularization. Concurrently, the anther releases young microspores from the tetrads (Fig. 5(f1)).

\section{Stage 4-pre-fertilization}

At 31 to 40 DAS, when ginseng leaves are fully expanded and the peduncle have reached its maximum height (Kim et al. 2015b; Fig. 2d), the "snowman shape" flower buds (Kim et al. 2015b; Fig. 2k) have stigmas of $1.0524 \pm 0.11 \mathrm{~mm}$ in length and ovules of $0.4722 \pm 0.01 \mathrm{~mm}$ in length (Figs. $2 \mathrm{r}$ and 6a), considered to be a common size in angiosperms ovules at
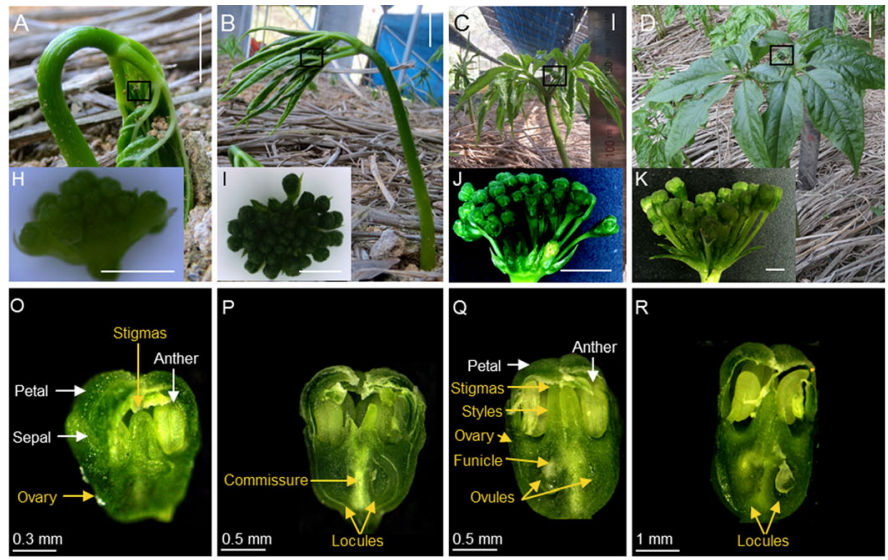

Fig. 2 Carpel development during plant growth in $P$. ginseng. a Initial stage, 1-5 DAS. b Developing stage, 10-14 DAS. c-e Maturing stage at 24 to 31 DAS (c), 31 to 40 DAS (d), and 40 to 45 DAS (e). f-g Mature to senescence stage at 45 to 50 DAS (f) and 50 to 90 DAS (g). h-n
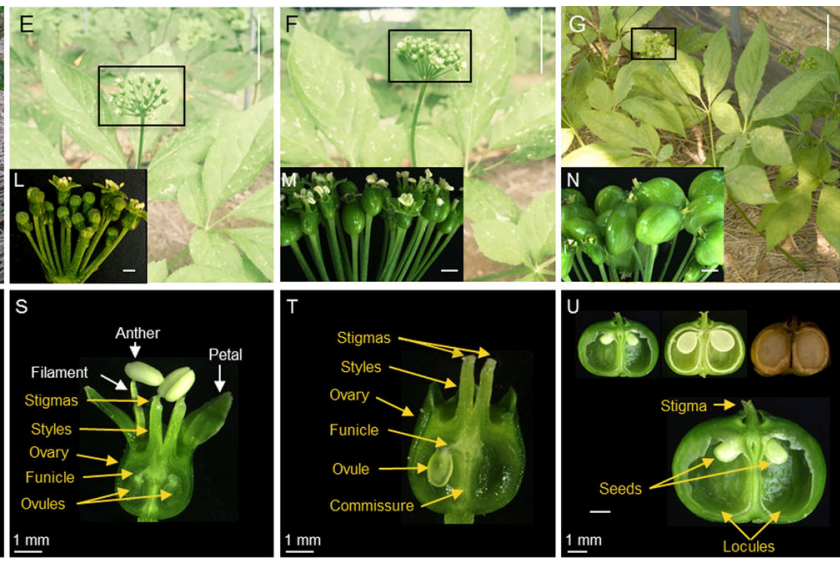

Inflorescence morphology at different plant developmental stages before fruit formation. o-u Morphogenesis of flower at different plant developmental stages before fruit formation. Scale bars $=1 \mathrm{~cm}(\mathbf{a}-\mathbf{c})$, $5 \mathrm{~cm}(\mathbf{d}-\mathbf{g}), 2 \mathrm{~mm}(\mathbf{h}-\mathbf{n}) . D A S$ days after sprouting 


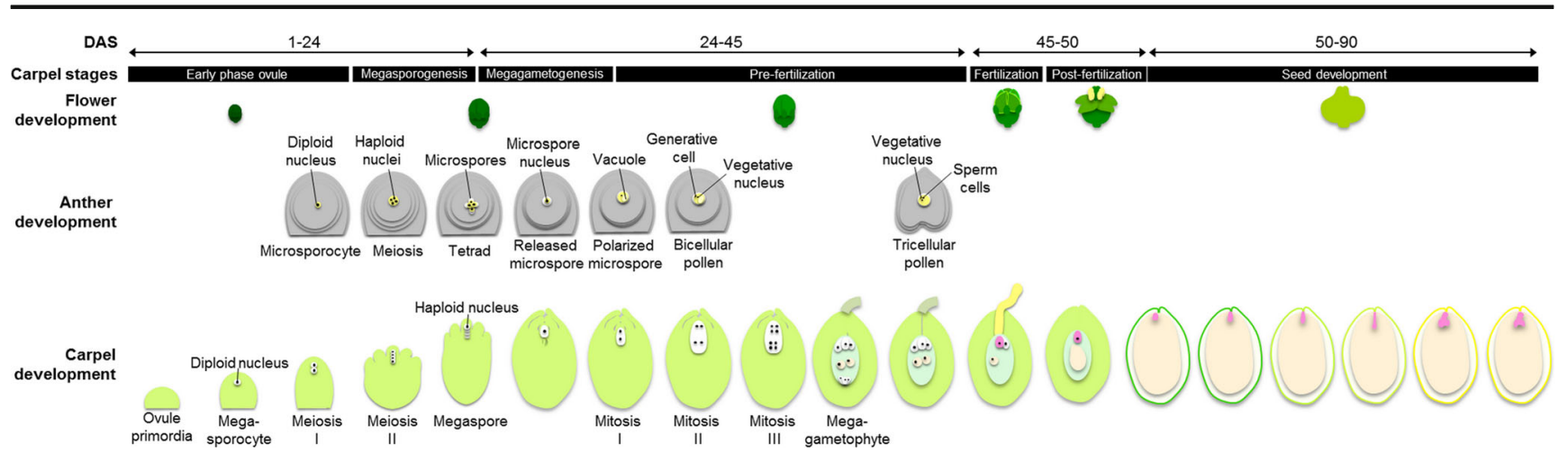

Fig. 3 Diagram of $P$. ginseng reproductive development and the stages of carpel development. Male developmental schemes were adapted from Kim et al. 2015b. DAS days after sprouting. Numbers correspond to anther developmental stages as described in Kim et al. 2015b. Structures are not drawn to scale

the time of fertilization (Endress 2011). Stage 4-I is defined as the stage when the ovule begins the formation of a vacuole and the antipodals (Fig. 6b, d). During stage 4-II, the antipodals degenerate, while the central cell, synergids, and egg cell appear (Fig. 6e). The last two mitotic divisions give rise to the cellularization process, where cells differentiate into different lineages: egg cell, central cell, and antipodals (Fig. $6 \mathrm{f}-\mathrm{k}$ ). In stage 4-III, the micropyle opens (Fig. 6c) to allow the entry of the pollen tube.

In the course of stages 4-I to 4-III, the microspores undergo vacuolation, first and second mitotic divisions, and the anther matures (Figs. 3 and $61-0$ ). At the end of stage 4-III, the anther starts to dehisce (Fig. 6i) and the flower starts to open (Fig. 6a).

\section{Stage 5-fertilization}

At 40 to 45 DAS, flowers in the inflorescence range from closed flower buds to fertilized flowers (Kim et al. 2015b; Figs. 2e, 1, and 7a). The fertilized flowers exhibit withered and pale yellow anthers, the filament has reached its maximum length (Kim et al. 2015b; Fig. 2s), and the stigma length is $2.2473 \pm 0.05 \mathrm{~mm}$ (Fig. 7b), at which point pollination takes place. During this stage, the fusion of sperm cells with the egg cell (to give rise to the zygote) and central cell (to give rise to the endosperm) takes place. We defined this stage as stage 5-I, when locules start to enlarge to make space for the fertilized ovules to grow (Fig. 2s).

\section{Stage 6-post-fertilization}

At 45 to 50 DAS, the inflorescence contains fertilized flowers (Fig. 2f, m) that each have a stigma of $2.1465 \pm 0.09 \mathrm{~mm}$ in length, enlarged ovules that are $1.387 \pm 0.02 \mathrm{~mm}$ wide and $0.8853 \pm 0.02 \mathrm{~mm}$ long (Fig. 2t). Eventually, the sepals, petals, and stamens wither and fall off (Fig. 7d). Stage 6-I was defined as when the synergids disappear and the egg cells break down (Fig. 7e, f). At stage 6-II, the two polar nuclei fuse with the second sperm cell to generate the endosperm (Fig. 7e, 1) with visible haustoria at the micropylar pole.

\section{Stage 7-seed development}

During 50 to 90 DAS, the inflorescence is full of green fruits that ultimately become yellow when matured (Fig. $2 \mathrm{~g}, \mathrm{n}$ ). The size of the fruit ranges from $5.1140 \pm 0.06 \mathrm{~mm}$ in length and $7.0416 \pm 0.03 \mathrm{~mm}$ in width, and the stigma is $2.0092 \pm 0.05 \mathrm{~mm}$ long (Fig. $2 \mathrm{u}$ ). In these fruits, the anthers and petals have completely disappeared, the locules have reached its maximum size, to around $2.7430 \pm 0.01 \mathrm{~mm}$ in width and $3.5177 \pm 0.11 \mathrm{~mm}$ in length, to enclose the developing seed, and the ovary subsequently hardens to form the seed coat (Fig. 8a). Stage 7-I was defined as when after fertilization the egg is transformed into the zygote of about $0.072 \mathrm{~mm}$ in length. Asymmetric cell division leads to an apical-basal axis. As the endosperm cellularizes, the cells begin to take on differential fates with internal endosperm cells that accumulate nutrient storage reserves (Fig. 8b, h). During stage 7-II, the zygote begins longitudinal division to a length of about $0.116 \mathrm{~mm}$ (Fig. 8c, i), and the endosperm is persistent. At stage 7-III, two rounds of longitudinal and one round of transverse divisions of the apical daughter cell produce the octant-stage embryo (Fig. 8d, j) that is thin and elongated $(\sim 0.143 \mathrm{~mm})$, where the length of the embryo proper is $0.056 \mathrm{~mm}$ and the suspensor is $0.087 \mathrm{~mm}$. At stage 7-IV, tangential division of each of the cells in the embryo proper produces inner cells and epidermis (protoderm) cells, maintaining the thin and elongated shape and the same size as the octant stage embryo, but the embryo properly increases to $0.104 \mathrm{~mm}$ in length and the suspensor becomes reduced to $0.039 \mathrm{~mm}$ in length, an indication that the embryo is at the dermatogen stage (Fig. 8e, k). At stage 7-V, after protodermal divisions in the region of the future cotyledons, the cotyledon initials form, and the embryo develops into the triangular stage (Fig. 8f, 1). At stage 7-VI, cotyledon initials are present, and the central cells begin to elongate and divide to form the provascular tissue. The embryo proper, with $0.170 \mathrm{~mm}$ in length and a suspensor of $0.078 \mathrm{~mm}$ in length, is enclosed by a cellularized endosperm, as the uppermost cells of the suspensor start to differentiate to form the hypophysis. The first two 


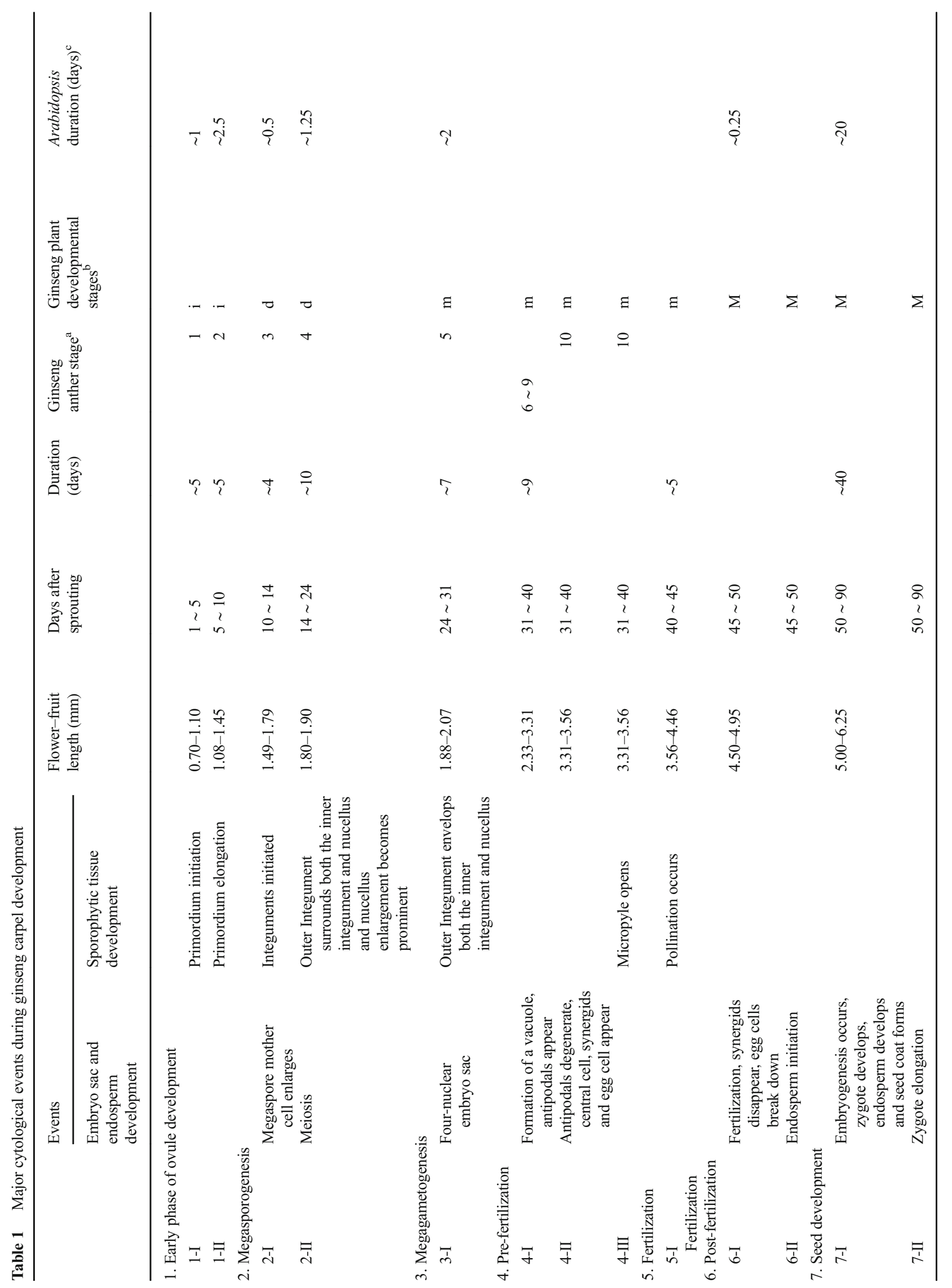




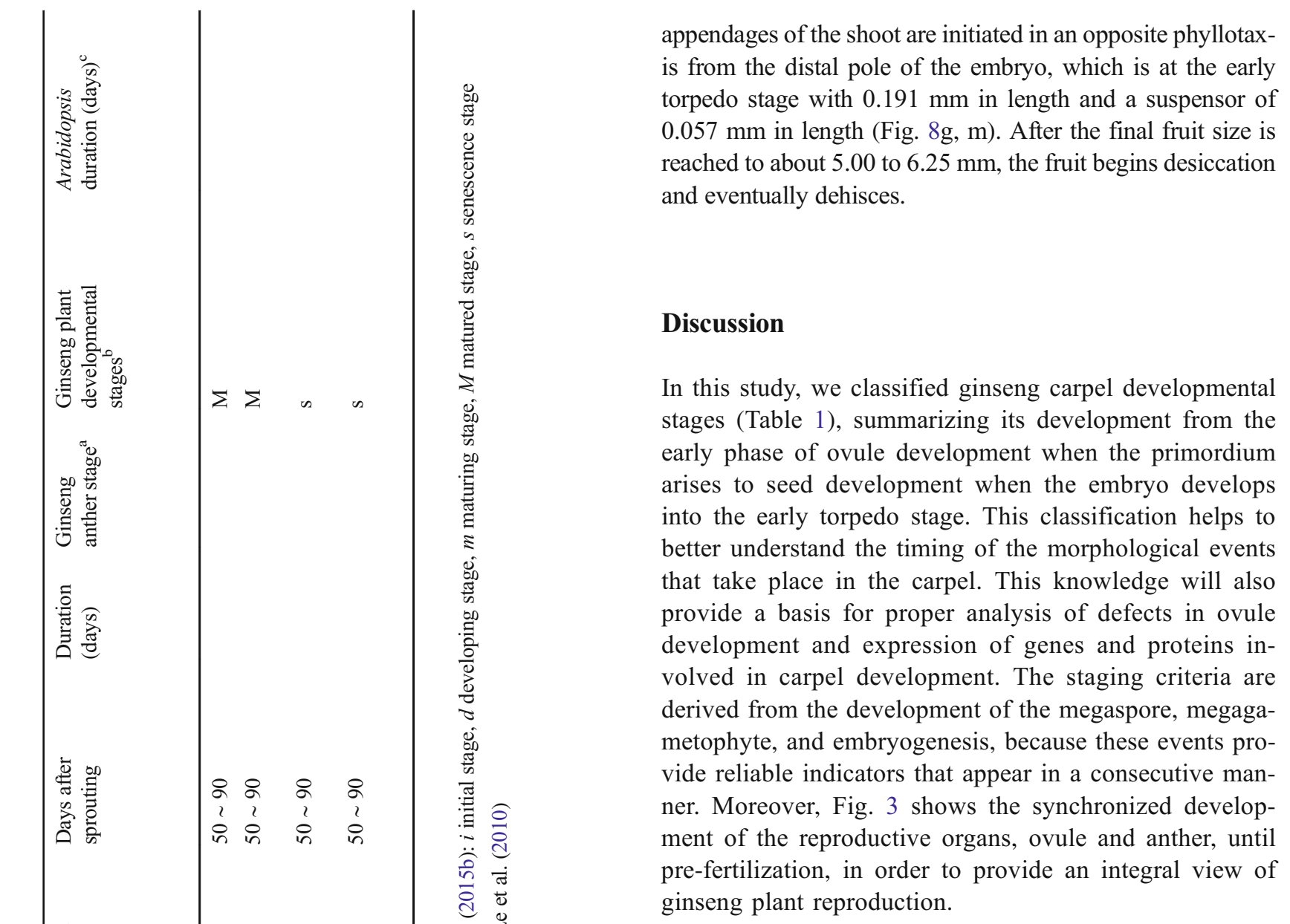

\section{Stages of carpel development}

Stage 1 comprises the early phase of ovule development until the primordia are enlarged in the pistil. Stage 2 covers megasporogenesis, starting with the enlargement of the megaspore mother cell and finishes with the outer integument surrounding both the inner integument and the nucellus. Stage 3 includes megagametogenesis, from the formation of the four-nuclear embryo sac to the development of the outer integument to enclose both the inner integument and the nucellus. Stage 4 involves pre-fertilization, starting with the formation of a vacuole and the emergence of the antipodals and concluding with the degeneration of the antipodals and emergence of the central cell, synergids, and egg cell. Stage 5 constitutes fertilization. Stage 6 denotes post-fertilization development, starting with fertilization and finishing with the initiation of endosperm. Stage 7 encompasses seed development from the zygote stage to the development of the early torpedo stage of the embryo. These stages cover the complete ontogeny of carpel development, an effort that was only reported for ovule development in Arabidopsis (Schneitz et al. 1995) and seed development in Panax quinquefolius (Qi et al. 2015). 

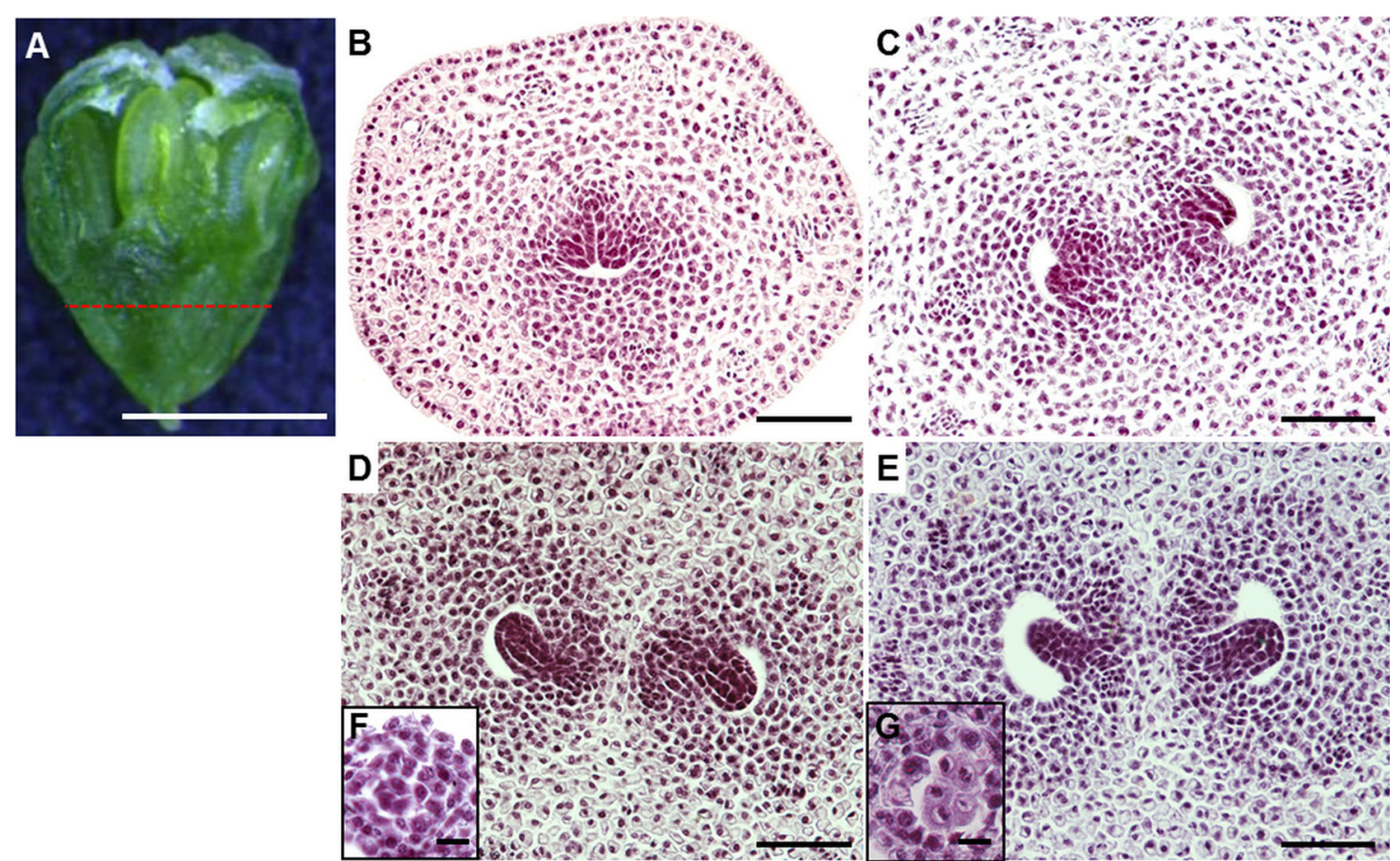

Fig. 4 Section analysis of early ovule development in $P$. ginseng, a Flower bud at the initial developmental stage. Dashed line indicates the position in the ovary where the transverse sections were made, $\mathbf{b}$ ovule primordium initiation, $\mathbf{c}$ separation of each ovule primordium in two opposite directions, $\mathbf{d}$ elongation of ovule primordium into finger-like, and $\mathbf{e}$ first meiotic division in the ovule primordium. $\mathbf{f}$ and $\mathbf{g}$ show the concurrent events observed in the anther as differentiation of anther layers (f) and microspore mother cell formation (g). Scale bars $=100 \mu \mathrm{m}(\mathbf{b}-\mathbf{e}), 20 \mu \mathrm{m}(\mathbf{f}, \mathbf{g})$
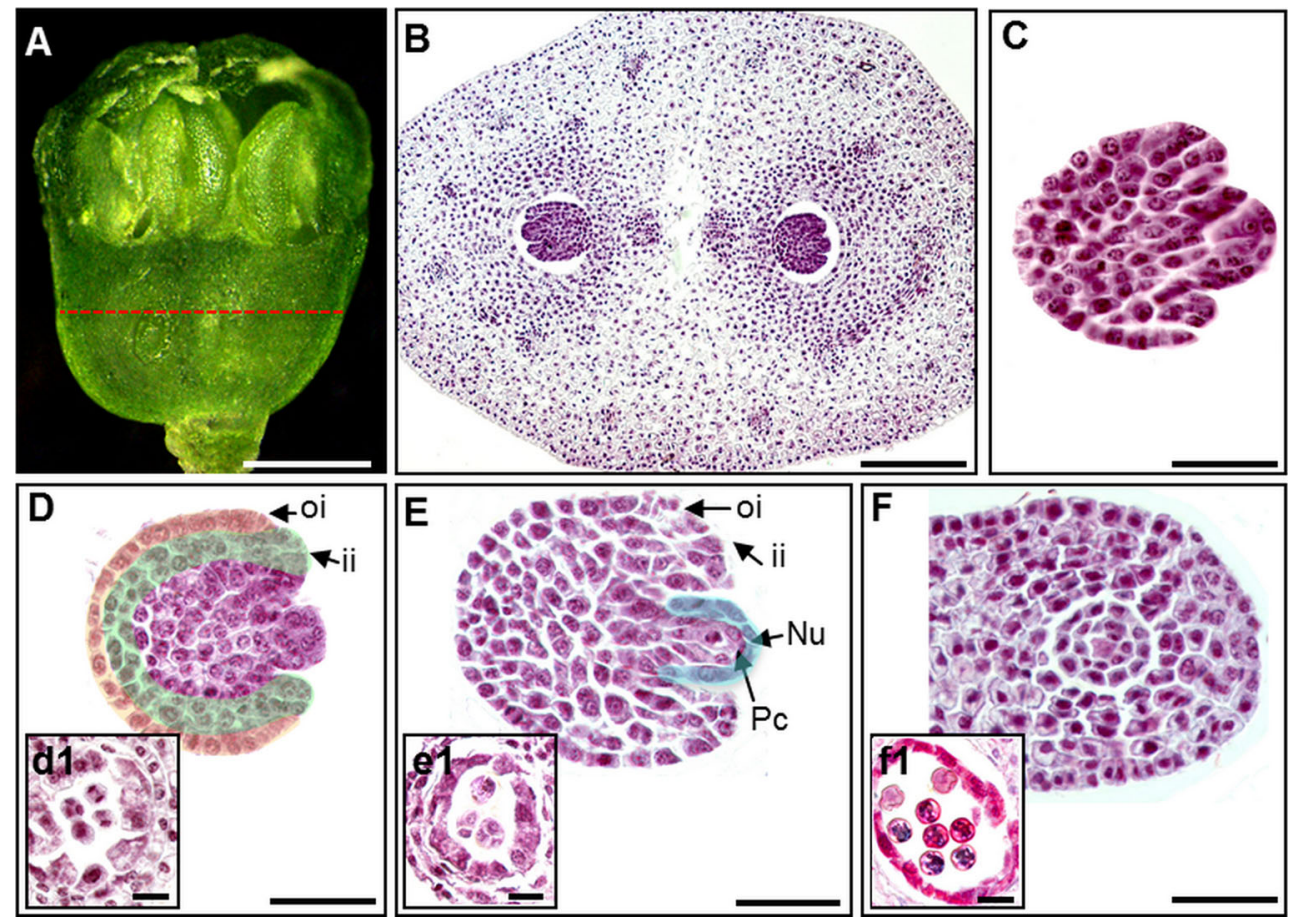

Fig. 5 Megasporogenesis and megagametogenesis in $P$. ginseng. a Flower bud at the developing stage. The red dashed line indicates the position in the ovary where transverse sections were made. b Megaspore mother cells of each locule; $\mathbf{c}$ initiation of the integuments that appear as small protuberances; d initiation of the integument elongation, showing that the two-cell-layered inner integument is slightly longer than the one-cell-layered outer integument;

e second meiotic division of the megaspore mother cell; $\mathbf{f}$ the outer integument completely encloses both the inner integument and nucellus. The concurrent events observed in the anther were $(d l)$ first meiotic division, (el) tetrad formation, and (fl) young microspore formation. Scale bars $=200 \mu \mathrm{m}(\mathbf{b}), 500 \mu \mathrm{m}(\mathbf{c}-\mathbf{f}), 20 \mu \mathrm{m}(d 1, e l, f 1)$. ii inner integument, $N u$ nucellus, oi outer integument, $P c$ parietal cell 
Fig. 6 Section analysis of prefertilization in $P$. ginseng. a Flower bud at the maturing stage. The red dashed line indicates the position in the ovary where longitudinal sections were made. b Formation of the vacuole; $\mathbf{c}$ opening of the micropyle; $\mathbf{d}$ formation of the antipodals; $\mathbf{e}$ degeneration of antipodals and formation of central cell and egg cell. $\mathbf{f}-\mathbf{h}$ Cellularization. $\mathbf{i}-\mathbf{k}$ enlargement of cellularization of $\mathbf{i}$ egg cell, $\mathbf{j}$ central cell, and $\mathbf{k}$ antipodals. The concurrent events observed in the anther are $\mathbf{I}$ microspore vacuolation, $\mathbf{m}$ mitotic division, $\mathbf{n}$ maturing pollen, and $\mathbf{o}$ release of mature pollen grains. Scale bars $=50 \mu \mathrm{m}$ (b-c), $20 \mu \mathrm{m}(\mathbf{d}-\mathbf{e}), 100 \mu \mathrm{m}(\mathbf{f}-$ h), $20 \mu \mathrm{m}$ (i-k), $20 \mu \mathrm{m}(\mathbf{l}-\mathbf{0})$. Ant antipodals, $C c$ central cell, $E c$ egg cell, Mic micropyle
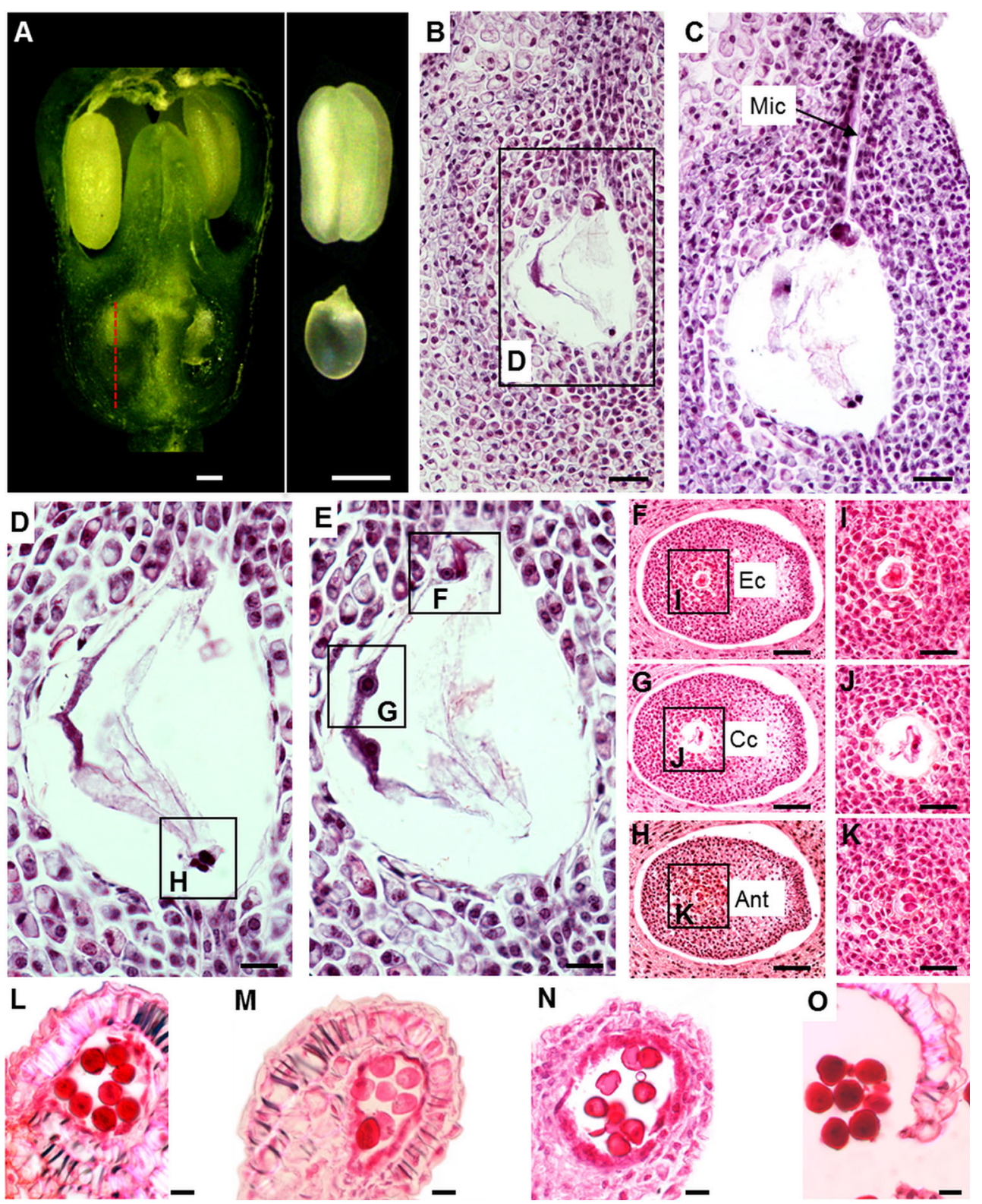

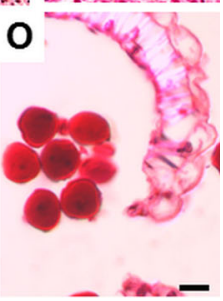

\section{Characteristics of ginseng carpel}

Synchrony of female and male gametophytic development was observed in this study to begin when ovule primordium undergoes elongation, at which point the anther undergoes the formation of the microsporocyte, and finishes at the end of pre-fertilization when cellularization is completed. The micropyle opens, and the anther releases mature pollen grains (Fig. 3). The significance of observing the synchrony in timing of female and male gametes derives from proving that it will not lead to failed fertilization. If some fertilization barriers are found, we can infer that they are originated from failures in the development of one of the gametophytes.
One interesting feature of the young ovule of $P$. ginseng is the presence of vascular bundles in a concentric circle adjacent to the ovary wall (Fig. 9a). This distribution pattern of the vascular bundles differs from those reported in other higher plants. For instance, they appear in an heterocarpellary position in Seemannaralia gerrardii (Oskolski et al. 2010), form an external circle in E. natalensis (Woodenberg et al. 2014), form an external and a central complex in Gaussia attetuata (Castaño et al. 2014), and form an arc in Vochysiaceae (Litt and Stevenson 2003). Anatomical studies of floral vasculature support the idea that in receptacular epigynous flowers, the vascular bundles provide traces to the floral appendages that run upward through the length of the ovary wall and then 
Fig. 7 Section analysis of fertilization and post-fertilization in $P$. ginseng. a Ovary at the end of the maturing stage. b Stigma showing remaining pollen grains attached. c Scanning electron microscopic observation of the outer surface of stigma. $\mathbf{d}$ Withered stamens and fallen sepals and petals. The red dashed line indicates the position in the ovary where longitudinal sections were made. e Degeneration of synergids, breaking down of egg cells, and initiation of endosperm. Also shown are haustoria at the micropylar end and cellular endosperm at the edges. $\mathbf{f}$ Enlargement of (e) showing the zygote and endosperm. Scale bars $=0.5 \mathrm{~cm}(\mathbf{a}, \mathbf{b}), 150 \mu \mathrm{m}(\mathbf{c})$, $1 \mathrm{~cm}(\mathbf{d}), 100 \mu \mathrm{m}$ (e), $50 \mu \mathrm{m}$ (f). $H s$ haustoria, Ce cellular endosperm
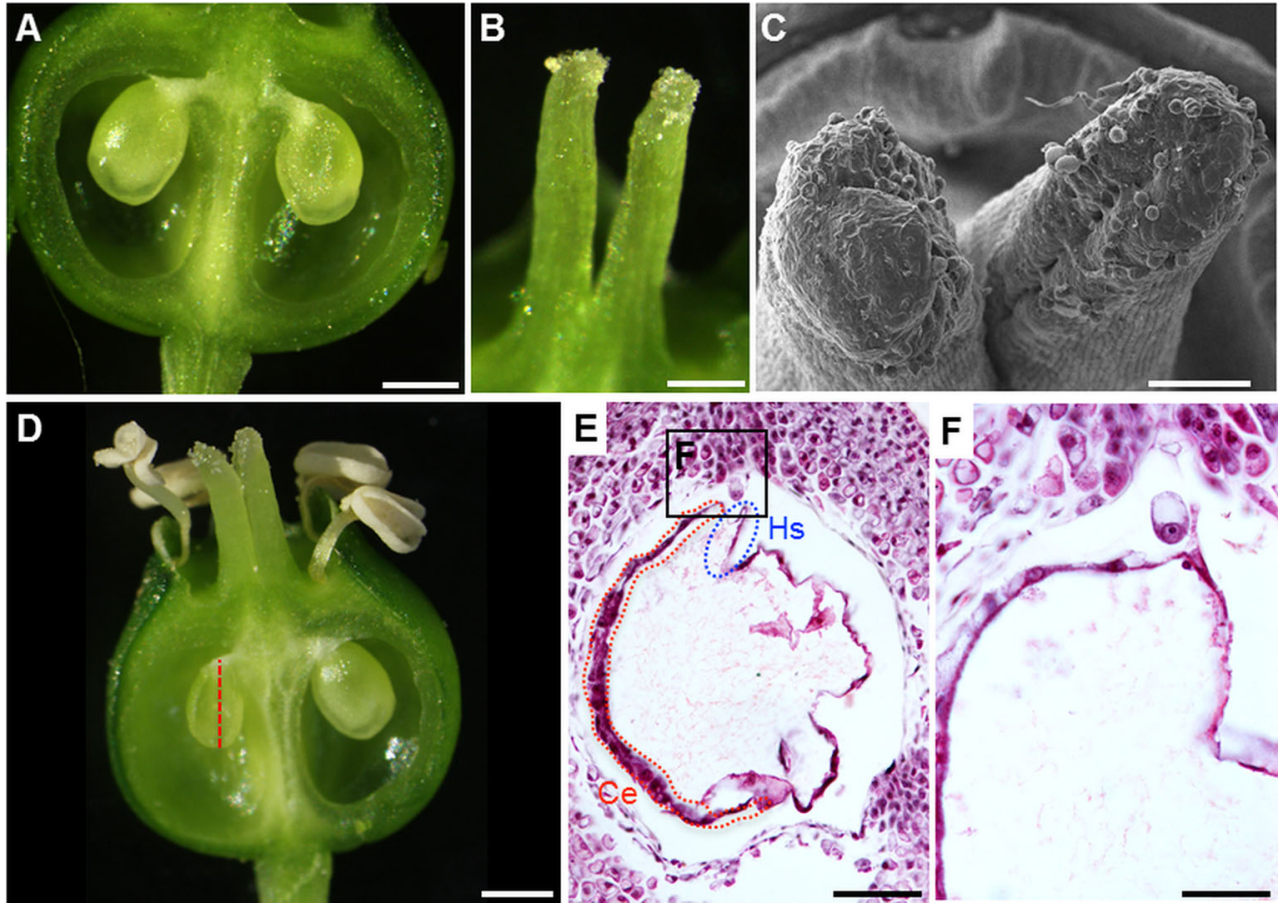
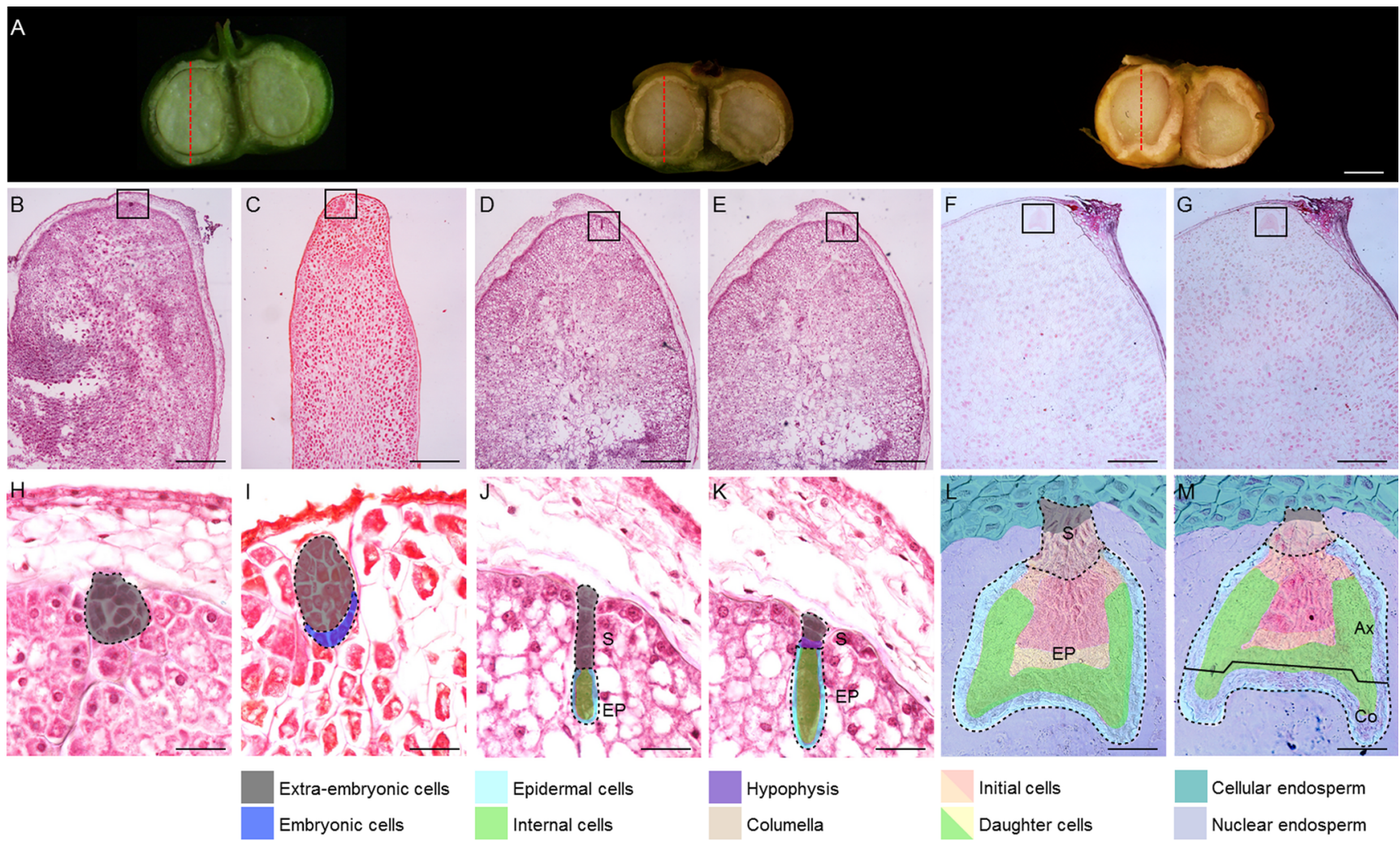

Fig. 8 Section analysis of seed development in $P$. ginseng. a Fruits showing completely wilted stamens and disappeared petals, ovary that has started to harden to form the seed coat, and the locules that have reached its maximum size to enclose the developing seed. The dashed line indicates the zygote, suspensor, and embryo proper. b-g Embryos during consecutive developmental stages of zygote (b), elongated zygote
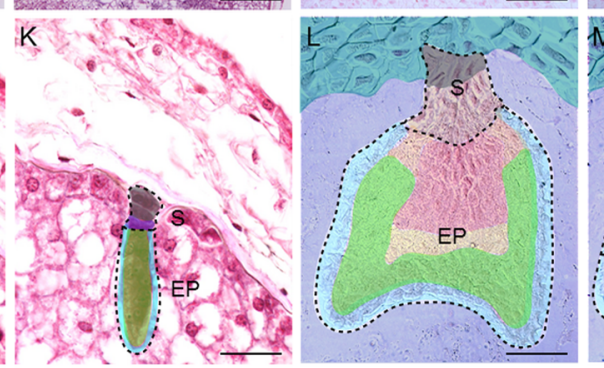

Hypophysis

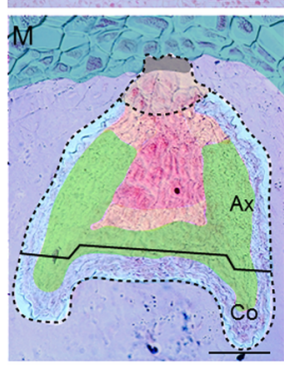

Cellular endosperm

Nuclear endosperm

(c), octant stage (d), dermagoten stage (e), triangular stage (f), and early torpedo stage (g). $\mathbf{h}-\mathbf{m}$ Enlargement of the boxes region in $\mathbf{b}-\mathbf{g}$ showing the embryo developmental stages. Scale bars indicate $2 \mathrm{~mm}(\mathbf{a}), 500 \mu \mathrm{m}$ (b-g), $50 \mu \mathrm{m}(\mathbf{h}-\mathbf{m}) . A$ axis, $C$ cotyledon, $C e$ cellular endosperm, $E P$ embryo proper, $N e$ nuclear endosperm, $S$ suspensor 
Fig. 9 Histological and ultrastructural analysis of P. ginseng carpel. a Cross section showing vascular bundles (circles) in the flower buds at stage 1. b Longitudinal section showing anatropous ovules that are slightly curved. c Fruit showing one aborted ovule after fertilization. d Longitudinal section showing the early torpedo stage of an embryo within the developing seed. Scale bars indicate $100 \mu \mathrm{m}(\mathbf{a}), 200 \mu \mathrm{m}(\mathbf{b})$, $1 \mathrm{~mm}(\mathbf{c})$, and $500 \mu \mathrm{m}(\mathbf{d})$
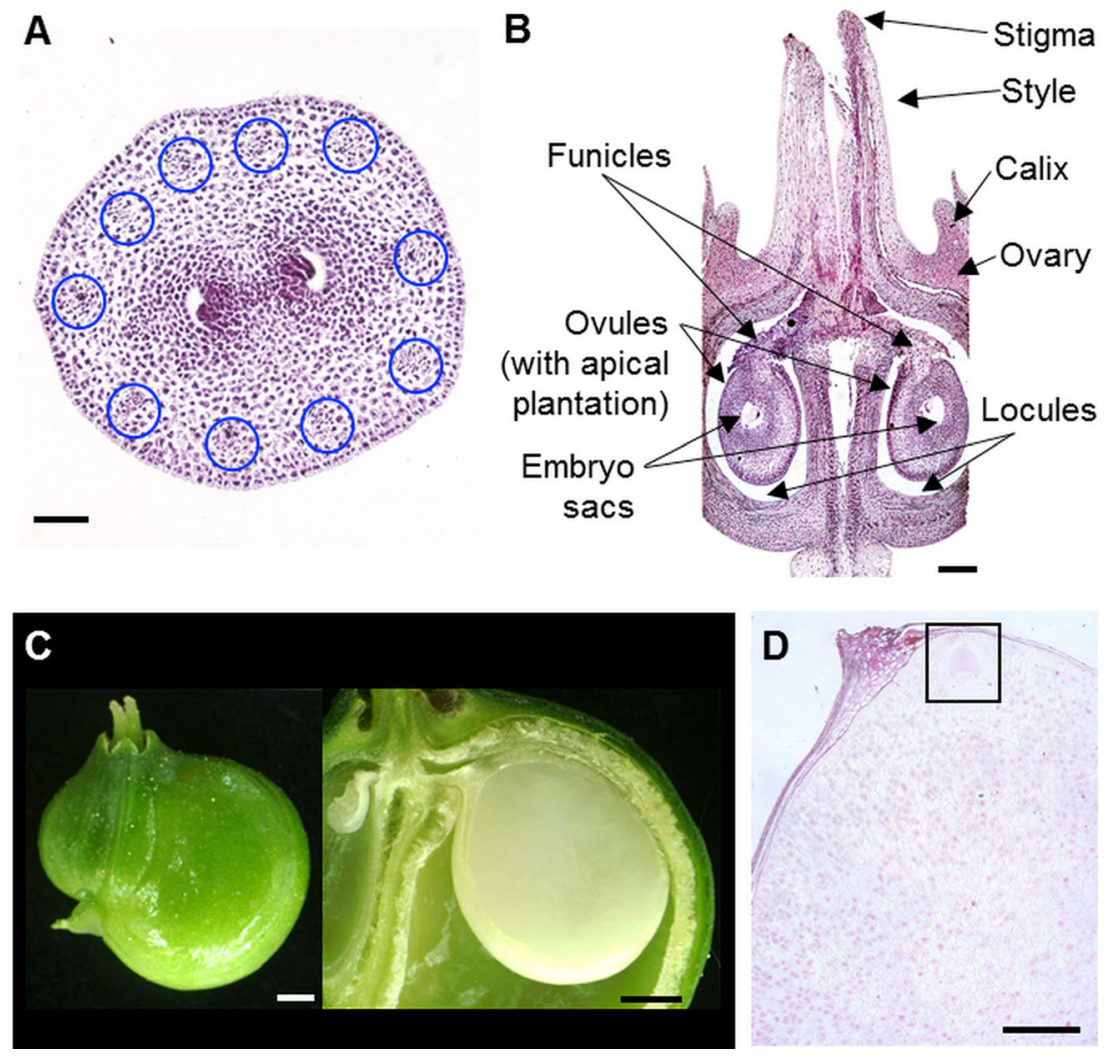

descend to supply nutrition to the ovule (Douglas 1957; Kaplan 1967; Costello and Motley 2004). Interestingly ginseng accumulates triterpene metabolite, and ginsenosides in vascular bundles of roots and stem (Kim et al. 2015b), especially ginsenoside $\mathrm{Re}$ in the ginseng fruit. This leads to the speculation that the presence of vascular bundles in the flower bud might have a function in the transport of water and metabolites such as ginsenosides, which may contribute to the expansion of developing ovules prior to fertilization. Further research needs to be carried out to confirm the involvement of vascular bundles in ginsenoside transport.

Megasporogenesis in $P$. ginseng proceeds with the formation of a parietal cell (Fig. 5e), which is a typical feature of polypetalous dicotyledons with bitegmic ovules. It is the division of the archesporial initially into primary parietal cells and primary sporogenous cells that results in the formation of the tenuinucellate ovule, which is consistent with the characteristic of Araliaceae (Johri et al. 1992).

The initiation of integuments is an essential event in ovule morphogenesis, because the tissues that ultimately will form the micropyle, nucellus, chalaza and funicle are also defined (Schneitz et al. 1995; Schneitz 1999; Endress 2011). The inner integument initiates slightly earlier than the outer integument (Fig. 5d). The outer integument originates from a subepidermal cell close to the dividing epidermal cell; cell division extends to neighboring subepidermal cells and the covering epidermals. The integuments continue their development and eventually enclose the nucellus completely. Although both the inner and outer integuments mostly contain two cell layers in angiosperms (Endress 2011), this feature differs between monocots and dicots. In dicots the outer integument mostly has two cell layers; in contrast, in monocots, it can contain two to ten cell layers, as reported for I. tenax (Wilson 2001), Triteleia sp. (Berg 2003), and $G$. attenuata (Castaño et al. 2014). The comparison of $P$. ginseng and other dicots shows that in $P$. ginseng, the outer integument only has one layer of cells, which is different from dicots such as Arabidopsis (Schneitz et al. 1995), Cytisus sp. (Rodríguez-Riaño et al. 2006), and Drosera x obovata (Rodondi et al. 2009), comprising a unique feature of $P$. ginseng. Moreover, we observed that the curvature of the ovule is subtle in $P$. ginseng and not as conspicuous as in other higher plants (Endress 2011) such as Triteleia sp. (Berg 2003), Cytisus sp. (Rodríguez-Riaño et al. 2006), I. tenax (Wilson 2001), and Drosera x obovata (Rodondi et al. 2009). In angiosperms, the outer integument is often thinner in orthotropous ovules than in anatropous ovules (Endress 2011), suggesting that $P$. ginseng might have evolved from plants with orthotropous ovules. Knowing the ovule curvature type is of great importance since its function is to bring the micropyle close to the funicle to enable a direct passage of the pollen tube, thereafter, the integuments become the seed coat to protect the embryo, assist in seed dissemination, and regulate seed germination (Kelley and Gasser 2009). In addition, the ovule has apical placentation (Fig. 9b), which is characteristic of $P$. ginseng because the most common placentation of the 
anatropous ovules is basal (Wilson 2001; Endress 2011; Musiał et al. 2013; Figueiredo et al. 2013). The features of the integuments show how $P$. ginseng carpel has evolved to develop advanced ovules that help the mobility of the pollen tube to be unprolonged and secure the movement during fertilization.

Another noteworthy observation is that in the transition from megasporogenesis to megagametogenesis, the ovule exhibits a twofold enlargement from 110 to $220 \mu \mathrm{m}$ in 10 days (Fig. 5c-f). A likely explanation of this enlargement is the subsequent growth of the embryo sac to prepare to form and encase the cell lineages (antipodals, central cell, synergids, and egg cell). The other observation is that at the very beginning of stage 7 , aborted ovules were observed. Although it is not commonly seen in seeds that $P$. ginseng produces, it is known to occur in Araliaceae (Johri et al. 1992) and P. quinquefolius (Schluter and Punja 2000), suggesting that post-fertilization events are likely responsible for abortion. Our observations provide evidence to assume that abortion may be originated from defects during pre-fertilization stage where the anther development undergoes the microspore vacuolation, mitotic division, maturing pollen, and pollen release. Or it may be a failure during cellularization in the carpel. These are the two main aspects for fertilization to occur, in cell lineages in the embryo sac and two sperm cells in the mature pollen grain.

\section{Characteristics of ginseng embryogenesis}

In this study, we have found three distinctive features of $P$. ginseng embryogenesis. First is the length of time that a complete embryo development requires. Unlike Arabidopsis, in which embryogenesis is completed typically within 20 days post-fertilization (Le et al. 2010), P. ginseng needs 40 days to reach the early torpedo stage. To achieve germination, the embryo needs up to 90 additional days of stratification (Baranov 1966; Li 1995; Kim et al. 2015a), leading to the question why it needs longer time to develop. Based on the Baskin and Baskin (1998) classification theory of seed dormancy, P. ginseng seeds belong to the morphophysiological dormancy class, where seeds have underdeveloped embryos and require treatments to break the dormancy. As a result, to promote anatomical development, stratification in $P$. ginseng is usually done in humidified sand for 3 months at $5{ }^{\circ} \mathrm{C}$ to complete embryo development and to achieve germination (Kim et al. 2015a).

The second feature of $P$. ginseng is the small size of the embryo relative to the seed size, leading to the question whether the size is related to the nutrition needed by the developing embryo. This characteristic is also observed in Zea mays, for which the endosperm persists through seed development and provides storage reserves during seedling growth (Kiesselbach 1949; Bai and Settles 2015). In contrast, Arabidopsis embryo consumes the endosperm reserves as it develops, degenerating most of the endosperm by seed maturity (Bai and Settles 2015). Small embryo relative to the size of the seed is likely to be an ancestral characteristic in angiosperms (Forbis et al. 2002) that has been kept in P. ginseng. Forbis et al. (2002) reported that five species of Araliaceae, including Acanthopanax sessiliflorus, Aralia hispida, Oplopanax horridium, P. quinquefolius, and Hedera helix, have a small embryo, with a 0.38 ratio between the size of the embryo and seed. Consistently, the seed of $P$. ginseng is filled mostly by endosperm with the embryo making up a small part of the seed volume. A likely explanation for the small embryo size in the albuminous seed lies in the unique life of Araliaceae family.

The third feature of $P$. ginseng is that at the early torpedo stage, the endosperm exhibits two types, nuclear and cellular, and the embryo grows in the nuclear endosperm (Figs. 8 and 9d), as what has been reported to occur in Panax wangianus (Venugopal et al. 2013). The embryogenesis type of $P$. ginseng is chenopodiad, where the embryo is generated from both basal and terminal cells. We observed some differences in embryogenesis of $P$. ginseng from study on P. quinquefolius by Qi et al. (2015). First is the size and shape of the embryo. At octant and dermatogen stages, the suspensor and embryo proper of $P$. ginseng embryo are both thinner and more elongated than that of $P$. quinquefolius, with the suspensor size difference responsible for the remarkable embryo size difference between the two species is at the octant stage. At the dermatogen stage, the embryo proper in $P$. ginseng is wider than in P. quinquefolius. The second difference is the suspensor. At the triangular and early torpedo stages, $P$. ginseng embryo retains the suspensor, while in $P$. quinquefolius it is already degenerated. However, both species show an embryo of about $0.200 \mathrm{~mm}$ at the final stage of seed development. The suspensor is morphologically diverse throughout the plant kingdom (Kawashima and Golberg 2010) and according to our observations, it can also differ between Panax species. The role of the suspensor in embryo development is essential, since it places the embryo proper into the endosperm cavity and connects the embryo proper to surrounding maternal and endosperm tissues, serving as a conduit for nutrients and growth regulators required for embryonic development (Kawashima and Golberg 2010). According to our observations, the suspensor completes earlier its contribution for the embryo development and undergoes programmed cell death in P. quinquefolius in comparison with $P$. ginseng, although the mechanisms responsible for this early shift remain to be determined.

Through this cytological analysis of $P$. ginseng carpel development, we have been able to propose a 7 -stage process for the development based on reliable indicators that appear in a consecutive manner throughout carpel development. Correlation of the development of female and male gametophytes and identification of unique characteristics of ginseng carpel/embryo development are also summarized. Our study may offer a valuable tool for the study of reproductive developmental in Araliaceae family and provide knowledge basis for ginseng breeding. 
Acknowledgements This research was supported by a grant from the Basic Science Research Program through the National Research Foundation (NRF), Ministry of Education, Republic of Korea, to YJ Kim (2016R1A6A3A11931858), an iPET grant from the Korea Institute of Planning and Evaluation for Technology in Food, Agriculture, Forestry and Fisheries, Republic of Korea, to DC Yang (112142-05-4-SB010), and a grant from the Ministry of Science and Technology, People's Republic of China, to JP Hu (2015DFG32560).

\section{Compliance with ethical standards}

Conflict of interest The authors declare that they have no conflict of interest.

\section{References}

Angenent GC, Colombo L (1996) Molecular control of ovule development. Trends Plant Sci 1(7):228-232

Bai F, Settles AM (2015) Imprinting in plants as a mechanism to generate seed phenotypic diversity. Front Plant Sci 5(780). doi:10.3389/fpls. 2014.00780

Baranov A (1966) Recent advances in our knowledge of the morphology, cultivation and uses of ginseng (Panax ginseng C. A. Meyer). Econ Bot 20(4):403-406

Baskin CC, Baskin JM (1998) Seeds: ecology, biogeography, and evolution of dormancy and germination. Academic Press, San Diego

Beeckman T, Viane R (2000) Embedding thin plant specimens for oriented sectioning. Biotech Histochem 75(1):23-26

Berg RY (2003) Development of ovule, embryo sac, and endosperm in Triteleia (Themidaceae) relative to taxonomy. Am J Bot 90(6):937-948

Castaño F, Stauffer F, Marquinez X, Crèvevoeur M, Collin M, Pintaud JC, Tregear J (2014) Floral structure and development in the monoecious palm Gaussia attenuata (Arecaeae; Arecoideae). Ann Bot 114(7):1483-1495

Coombe BG (1976) The development of fleshy fruits. Ann Rev Plant Physiol 27(1976):507-528

Costello A, Motley TJ (2004) The development of the superior ovary in Tetraplasandra (Araliaceae). Am J Bot 91(5):644-655

de Oliveira RR, Cesarino I, Mazzafera P, Dornelas MC (2014) Flower development in Coffea arabica L.: new insights into MADS-box genes. Plant Reprod 27(2):79-94

Douglas GE (1957) The inferior ovary, II. Bot Rev 23:1-41

Dresselhaus T, Sprunck S, Wessel M (2016) Fertilization mechanisms in flowering plants. Curr Biol 26(3):125-139

Endress PK (2011) Angiosperm ovules: diversity, development, evolution. Ann Bot 107(9):1465-1489

Figueiredo RC, Masullo FA, Cardoso Vieira R, De Toni KLG (2013) Development of carpels and ovules in Psychotria carthagenensis (Psychotrieae) and Rudgea macrophylla (Palicoureeae) (Rubioideae, Rubiaceae). South African J Bot 84:110-114

Forbis TA, Floyd SK, De Queiroz A (2002) The evolution of embryo size in angiosperms and other seed plants: implications for the evolution of seed dormancy. Evolution 56(11):2112-2125

Igersheim A, Cichocki O (1996) A simple method for microtome sectioning of prehistoric charcoal specimens, embedded in 2- hydroxyethyl methacrylate (HEMA). Rev Palaeobot Palynol 92:389-393

Johri BM, Ambegaokar KB, Srivastava PS (1992) Comparative embryology of angiosperms, vol 1/2. Springer-Verlag, Berlin Heidelberg, Berlin

Kaplan DR (1967) Floral morphology, organogenesis and interpretation of the inferior ovary in Downingia bacigalupii. Am J Bot 54(10): $1274-1290$

Kawashima T, Golberg RB (2010) The suspensor: not just suspending the embryo. Trends Plant Sci 15(1):23-30
Kelley DR, Gasser CS (2009) Ovule development: genetic trends and evolutionary considerations. Sex Plant Reprod 2(4):229-234

Kiesselbach TA (1949) The structure and reproduction of corn. Research bulletin 161 Lincoln: Agricultural Experiment Station, University of Nebraska College of Agriculture, Nebraska

Kim YJ, Zhang D, Yang DC (2015a) Biosynthesis and biotechnological production of ginsenosides. Biotechnol Adv 33(6):717-735

Kim YJ, Jang MG, Zhu L, Silva J, Zhu X, Sukweenadhi J, Kwon WS, Yang DC, Zhang D (2015b) Cytological characterization of anther development in Panax ginseng Meyer. Protoplasma. doi:10.1007/ s00709-015-0869-3

Kim YJ, Silva J, Zhang D, Shi J, Joo SC, Jang MG, Kwon WS, Yang DC (2016) Development of interspecies hybrids to increase ginseng biomass and ginsenoside yield. Plant Cell Rep 35(4):779-790

Koizumi A, Yamanaka K, Kawano S (2009) Carpel development in a floral mutant of dioecious Silene latifolia producing asexual and female-like flowers. J Plant Physiol 166(16):1832-1838

Kubo T, Fujita M, Takahashi H, Nakazono M, Tsutsumi N, Kurata N (2013) Transcriptome analysis of developing ovules in rice isolated by laser microdissection. Plant Cell Physiol 54(5):750-765

Le BH, Cheng C, Bui AQ, Wagmaister JA, Henry KF, Pelletier J, Kwong L, Belmonte M, Kirkbride R, Horvath S, Drews GN, Fischer RL, Okamuro JK, Harada JJ, Goldberg RB (2010) Global analysis of gene activity during Arabidopsis seed development and identification of seed-specific transcription factors. Proc Natl Acad Sci U S A 107(18):8063-8070

Li TSC (1995) Asian and American ginseng-a review. Hortechnol 5(1): 27-34

Litt A, Stevenson DW (2003) Floral development and morphology of Vochysiaceae. I. The structure of the gynoecium. Am J Bot 90(11):1533-1547

Musiał K, Płachno BJ, Świątek P, Marciniuk J (2013) Anatomy of ovary and ovule in dandelions (Taraxacum, Asteraceae). Protoplasma 250(3):715-722

Oskolski AA, Sokoloff DD, Van Wyk BE (2010) False paracarpy in Seemannaralia (Araliaceae): from bilocular ovary to unilocular fruit. Ann Bot 106(1):29-36

Qi J, Sun P, Liao D, Sun T, Zhu J, Li X (2015) Transcriptomic analysis of American ginseng seeds during the dormancy release process by RNA-Seq. PLoS One 10(3). doi:10.1371/journal.pone.0118558

Reiser L, Fischer RL (1993) The ovule and the embryo sac. Plant Cell 5(10):1291-1301

Robert HS, Crhak Khaitova L, Mroue S, Benková E (2015) The importance of localized auxin production for morphogenesis of reproductive organs and embryos in Arabidopsis. J Exp Bot 66(16):50295042

Rodondi G, Beretta M, Andreis C (2009) Ovule and pollen development in the natural hybrid Drosera x obovata Mert. \& Koch (Droseraceae) and its parents. Flora 204(9):685-691

Rodríguez-Riaño T, Valtueña FJ, Ortega-Olivencia A (2006) Megasporogenesis, megagametogenesis and ontogeny of the aril in Cytisus striatus and C. multiflorus (Leguminosae: Papilionoideae). Ann Bot 98(4):777-791

Rudall PJ, Remizowa MV, Beer AS, Bradshaw E, Stevenson DW, Macfarlane TD, Tuckett RE, Yadav SR, Sokoloff DD (2008) Comparative ovule and megagametophyte development in Hydatellaceae and water lilies reveal a mosaic of features among the earliest angiosperms. Ann Bot 101(7):941-956

Sachs J, Bennett AW (2011) A text-book of botany: morphological and physiological. Cambridge University Press, Cambridge

Schluter C, Punja ZK (2000) Floral biology and seed production in cultivated North American ginseng (Panax quinquefolius). J Amer Hort Sci 125(5):567-575

Schneitz K (1999) The molecular and genetic control of ovule development. Curr Opin Plant Biol 2(1):13-17 
Schneitz K, Huiskamp M, Pruitt RE (1995) Wild-type ovule development in Arabidopsis thaliana: a light microscope study of cleared wholemount tissue. Plant J 7(5):731-749

Singh G (2010) Plant systematics an integrated approach. CRC Press, Delhi

Sokoloff DD, Oskolski AA, Remizowa MV, Nuraliev MS (2007) Flower structure and development in Tupidanthus calyptratus (Araliaceae): an extreme case of polymery among asterids. P1 Syst Evol 268(1): 209-234

Venugopal N, Ahuja P, Lalchhanhimi (2013) A unique type of endosperm in Panax wangianus S. C. Sun. J Plant Develop 20(2013):45-50

Vivian-Smith A, Luo M, Chaudhury A, Koltunow A (2001) Fruit development is actively restricted in the absence of fertilization in Arabidopsis. Development 128(12):2321-2331

Wang ZF, Ren Y (2008) Ovule morphogenesis in Ranunculaceae and its systematic significance. Ann Bot 101(3):447-462

Wilson CA (2001) Floral stages, ovule development, and ovule and fruit success in Iris tenax, focusin on var. Gormanii, a taxon with low seed set. Am J Bot 88(12):2221-2231

Woodenberg WR, Berjak P, Pammenter NW, Farrant JM (2014) Development of cycad ovules and seeds. 2. Histological and ultrastructural aspects of ontogeny of the embryo in Encephalartos natalensis. Protoplasma 251(4):797-816

Wu X, Liu J, Li D, Liu CM (2016a) Rice caryopsis development I: Dynamic changes in different cell layers. J Integr Plant Biol 58(9): 772-785

Wu X, Liu J, Li D, Liu CM (2016b) Rice caryopsis development II: Dynamic changes in the endosperm. J Integr Plant Biol 58(9):786798

Yu SC, Kim WK (1992) Structural changes and histochemical study of endosperm on Panax ginseng C. A. Meyer during embryo development. Korean J Ginseng Sci 16(1):37-43

Zhang Y, Liang W, Shi J, Xu J, Zhang D (2013) MYB56 encoding a R2R3 MYB transcription factor regulates seed size in Arabidopsis thaliana. J Integr Plant Biol 55(11):1166-1178

Zhang J, Tang W, Huang Y, Niu X, Zhao Y, Han Y, Liu Y (2015) Down-regulation of a LBD-like gene, OsIG1, leads to occurrence of unusual double ovules and developmental abnormalities of various floral organs and megagametophyte in rice. J Exp Bot 66(1):99-112 